\title{
Combination therapy in cancer: effects of angiogenesis inhibitors on drug pharmacokinetics and pharmacodynamics
}

\author{
Ilaria Fuso Nerini ${ }^{\dagger}$, Marta Cesca ${ }^{\dagger}$, Francesca Bizzaro and Raffaella Giavazzi ${ }^{*}$
}

\begin{abstract}
Validated preclinical studies have provided evidence that anti-vascular endothelial growth factor (VEGF) compounds enhance the activity of subsequent antitumor therapy, but the mechanism of this potentiation is far from clear. The most widespread explanation is enhanced delivery of therapeutics due to vascular remodeling, lower interstitial pressure, and increased blood flow. While the antiangiogenic effects on vascular morphology have been fairly consistent in both preclinical and clinical settings, the improvement of tumor vessel function is debated. This review focuses on the effect of anti-VEGF therapy on tumor microenvironment morphology and functions, and its therapeutic benefits when combined with other therapies. The uptake and spatial distribution of chemotherapeutic agents into the tumor after anti-VEGF are examined.
\end{abstract}

Keywords: Combination therapies, Angiogenesis inhibitors, Drug delivery, Tumor microenvironment

\section{Background}

Deregulation of angiogenesis is a hallmark of cancer which causes an abnormal microenvironment, promoting tumor progression and affecting the delivery of chemo-, radio-, and immunotherapy [1]. Tumor angiogenesis offers an attractive therapeutic target, shared by most cancers. Angiogenesis inhibitors have therefore been investigated and exploited for their therapeutic application in most human tumors. The most validated antiangiogenic approaches act on the vascular endothelial growth factor (VEGF) axis, blocking VEGF or its receptors (VEGFRs) [2,3]. Examples include the humanized anti-VEGF monoclonal antibody bevacizumab, approved in the clinic for a number of malignancies [4], and the VEGF-Trap protein aflibercept formed by the fusion of the immunoglobulin domain of VEGFR with the human IgG Fc fragment, approved for second-line treatment of metastatic colorectal cancer (CRC) [5]; both compounds are in general used in combination with chemotherapy. A

\footnotetext{
*Correspondence: raffaella.giavazzi@marionegri.it

${ }^{\dagger}$ Illaria Fuso Nerini and Marta Cesca contributed equally to this work Department of Oncology, IRCCS-Mario Negri Institute for Pharmacological Research, Via La Masa 19, 20156 Milan, Italy
}

number of small molecules, such as sunitinib, sorafenib, pazopanib, and cediranib, inhibit the tyrosine kinase activity of VEGFR and have been approved as single therapies [6,7]; due to frequent severe adverse effects, they are rarely used in combination with chemotherapy.

Because of the structural similarities between VEGFR and other receptor tyrosine kinases (RTKs), these receptor tyrosine kinase inhibitors (RTKIs) often inhibit multiple targets, thus affecting not only the tumor vasculature but other components of the tumor stroma and neoplastic cells themselves. On the other hand, some drugs that were developed for their cytotoxic effects on tumor cells also induce antiangiogenic responses by down-regulating pro-angiogenic factors or by directly targeting endothelial cells. For example, paclitaxel and other tubulin-binding agents target tumor vessels, inhibiting endothelial cell functions related to angiogenesis, at lower concentrations than those required for the anti-mitotic activity [8].

We review therapeutic strategies that use antiangiogenics in combination with chemotherapy to enhance their potential. We focus on anti-VEGF compounds, particularly bevacizumab, since they are the main angiogenesis inhibitors used in clinical application combined with chemotherapy. We illustrate the antitumor effects of the 
combination, taking into account the effects of VEGF inhibition on pharmacokinetics, biodistribution, and tumor penetration of chemotherapy.

\section{Pharmacodynamic and functional effects of antiangiogenics on tumor microenvironment}

The vasculature network in tumors is structurally abnormal, with tortuousities and dilatations, disproportionate branching, and arteriovenous shunts. The angiogenic process, driven by high levels of growth factors and inflammatory cytokines, is extensive, and the newly formed vessels are extremely leaky due to defective pericyte coverage and discontinuous basement membranes. The structural abnormalities of the tumor vasculature, together with the compression of blood vessels by cancer cells, cause functional impairment of blood flow, such as temporary stagnation, turbulent flow, local hemorrhages, and high outflow of plasma macromolecules. The consequences are increased tumor interstitial fluid pressure (TIFP) and the formation of hypoxic/necrotic regions [9]. These structural and functional aberrations occur in a heterogeneous spatial (in different areas of tumor tissue) and temporal (during tumor growth and progression) manner.

Antiangiogenic therapy restores the balance between pro- and antiangiogenic molecules and the vascular architecture of tumor tissue by pruning immature vessels and remodeling the remaining ones [10,11]. Several preclinical studies agree on the modifications induced by antiangiogenics (e.g. bevacizumab) in tumor vasculature, both macroscopically and microscopically. In different tumor models, antiangiogenic treatment reduced the density, diameter, and tortuosity of capillaries and induced vessel maturation by re-establishing pericyte and basement membrane coverage [12].

Clinical studies have provided evidence of vascular changes in cancer patients treated with antiangiogenic agents, despite the difficulties of biopsying tumors after pharmacologic therapy [13-17]. Tumor biopsies from non-metastatic CRC patients from a phase I study showed evidence of the antiangiogenic effects of antiVEGF therapy with bevacizumab [18]. Pathologic analysis indicated that bevacizumab reduced tumors from hyperemic, hemorrhagic lesions to pale masses, and microscopically led to an increase in pericyte coverage, favoring vessel maturation and stabilization [18].

Whether these morphological changes are accompanied by functional modifications of the tumor vasculature is debated. Hypothetically, antiangiogenics can improve blood perfusion, with a consequent drop in TIFP and alleviation of hypoxia [11, 12]. This suggests that the blood transport capacity of vessels that survive antiangiogenic treatment is increased, favoring the arrival of oxygen and nutrients to tumor tissues. If anti-VEGF therapy really improves the blood flow and oxygenation of tumor tissue, then the question arises whether it may actually favor tumor growth. Although this is possible in theory, there are no studies describing promotion of tumor growth with antiangiogenics, rather the contrary is true. This is probably due to the long-term inhibition of new vessel formation that starves the tumor after a temporary favorable increase in blood flow and oxygenation.

In preclinical studies, bevacizumab reduced the tumor uptake of fluorescent dyes-analyzed by microscopy, or of contrast agents-seen with vital imaging techniques [19-21]. Using intravital multiphoton microscopy to monitor the transit velocity of erythrocytes, it was seen that bevacizumab increased blood flow velocity and reduced vascular permeability in the tumor [22]. Arterial spin labeling magnetic resonance imaging (ASLMRI) showed a specific decrease of tumor perfusion after bevacizumab, which was associated with the reduction of vessel diameter observed with histological analysis [23]. Clinical studies reported reduced penetration of contrast agents in the neoplastic bulk, independently of tumor shrinkage [24-29]. These effects are probably caused by vessel constriction, due to the suppression of nitric oxide production by bevacizumab [30], and/or the reduction of vessel permeability because of VEGF sequestration [31]. Changes in tumor perfusion after angiogenesis inhibition can have predictive value in patients. Glioblastoma patients with increased tumor blood perfusion are those most likely to benefit from antiangiogenic treatment [32].

Evaluating downstream effects of antiangiogenics on tumor tissue is difficult. Reliable methods to measure TIFP are still lacking. Wick-in-needle (WIN), which is the best standard to quantify TIFP, is limited by its invasiveness causing tissue damage that makes measurement untrustworthy [33]. Despite this problem, several experimental studies have reported decreases in TIFP after treatment with VEGF antagonists [9, 18, 20,34].

Contrasting results were obtained regarding the effects of angiogenesis inhibitors on tumor hypoxia. The different outcomes can be explained by the kinetics of the pharmacodynamic effects of antiangiogenics. The improvement in tumor oxygenation seems to last 2-4 days after anti-VEGF treatment [11]. At later times, increased intratumoral hypoxia was reported after bevacizumab treatment, probably due to the reduction of vessel density [35]. The transient drop in tumor hypoxia can be exploited to enhance the efficacy of radiotherapy [36]. There is also preclinical evidence that combining antiangiogenic agents with immunotherapy can improve the response, probably due to a reduction in tumor tissue hypoxia that favors the delivery of immune effector cells [37]. 


\section{Antiangiogenesis in combination with chemotherapy improves anticancer efficacy}

Preclinical studies reported responses in different tumor models after treatment with anti-VEGF monoclonal antibodies [12], and these were significantly better when combined with other treatment modalities, mainly chemotherapy [20, 34, 38-40]. In the clinical setting, antiVEGF has been proven effective as monotherapy only in certain cancers [41], but, added to first-line chemotherapy, it significantly improved clinical outcomes in different malignancies [42-45]. Bevacizumab has now been approved in combination with standard chemotherapy for patients with metastatic CRC [46], recurrent/advanced non-small cell lung cancer (NSCLC) [47], advanced cervical cancer [48], and advanced ovarian cancer [49-52], although its effectiveness is limited and lower than expected, especially in end-stage tumors. In general, angiogenesis inhibitors, and bevacizumab in particular, can be administered for extended periods safely and with manageable toxicity, so the potential benefit of the treatment is not limited by increased adverse events.

Several explanations have been proposed for the mechanisms by which antiangiogenic agents boost the efficacy of chemotherapy: (a) a direct effect on neoplastic cell viability and induction of cytotoxicity independently of the vascular effects [22]; (b) impairment of the tumor cell's ability to repopulate between successive courses of chemotherapy [53]; (c) block of pro-survival signals and consequent chemosensitizing effect on endothelial cells, leading to disruption of vessels and starvation of neoplastic cells [38]; (d) "normalization" of the vascular microenvironment causing TIFP to drop and increasing intratumoral delivery of chemotherapy $[54,55]$; (e) temporary improvement of the oxygen and nutrient supply to tumor cells that renders them more sensitive to the cytotoxic activity [56]; (f) killing or inhibiting the mobilization of pro-angiogenic bone marrow-derived circulating endothelial progenitors [57]; (g) stimulation of the host immune response against the tumor by improving tumor delivery of immune cells and/or alleviating the tumor immunosuppressive microenvironment [58].

Alarmingly, some preclinical studies reported increased dissemination and metastases after VEGF/VEGFR inhibition, mainly with RTKIs [59-61] and in a neoadjuvant setting or when distant metastases are not established yet [62]. This seems to be counteracted by an appropriate combination with certain cytotoxic drugs [62]. Experimental evidence of increased invasion and metastasis after bevacizumab is not consistent $[40,63]$. Accordingly, clinical trials have not yet reported any increase in malignancy on VEGF inhibition [64], probably because some antiangiogenics are used in an adjuvant setting (e.g., RTKIs) and/or in combination with chemotherapy (e.g., bevacizumab). Several trials indicate that prolonged progression-free survival and improved response rates after antiangiogenic therapy are not always translated into an overall survival benefit $[4,65]$.

Optimization of the treatment schedule combining antiangiogenics and cytotoxics is becoming increasingly important to achieve efficacy. Preclinical and clinical evidence indicates that the benefit of angiogenesis inhibition is transient, and there is only a narrow window of opportunity during when synergy with chemotherapy can be achieved [11]. The optimal dosing of the antiangiogenic agent is also critical, as excessive suppression of the tumor vasculature may be counterproductive [37]. Improved clinical responses have been observed when chemotherapy was combined with low- rather than highdose bevacizumab [66].

\section{Effects of antiangiogenics on pharmacokinetics and tumor uptake of chemotherapy}

In terms of drug distribution, one would expect the vascular access of anticancer drugs to tumors to be impaired by inhibiting angiogenesis. However, the enhanced response to chemotherapeutics when given in combination with antiangiogenic compounds suggests that they do not necessarily reduce drug delivery to tumor tissue, but rather the opposite. The "normalization" theory provides an explanation for this apparent paradox, according to which an appropriate dose of antiangiogenic agent can restore normal blood flow and reduce TIFP, thus favoring the penetration of cytotoxic agents [11].

Although the effects of antiangiogenic therapy on the remodeling of vascular architecture have been demonstrated in various preclinical models, the consequences on drug distribution are often under-explored. Table 1 summarizes some in vivo experimental studies in which anti-VEGF antibodies were administered prior to antitumor agents and concentrations of the second drug in the tumor were measured with different methods. It is hard to compare the results because of the different tumor models and histotypes, the angiogenesis inhibitor dosages, and the combination schedules. Most studies agree on the morphological vessel changes after anti-VEGF treatment, such as decreased vessel density and greater pericyte coverage, but this is not always associated with functional modifications, such as increases in vessel perfusion and permeability. Results are discordant in terms of drug delivery to the tumor: some studies show increased uptake after antiangiogenic therapy [20, 34, 67-71], but others report reduced drug delivery [72-77]. Enhanced tumor uptake of chemotherapeutics was concomitant in some instances with improvement of vessel functionality $[68,78]$, whereas in other cases there was worsening of perfusion/permeability [34, 69]. Inefficient 
drug delivery was often associated with the reduction of tumor perfusion or vessel permeability.

We and others have shown that the concentrations of small molecules (cisplatin [75], paclitaxel [77], or doxorubicin [77]) in tumors were decreased after bevacizumab treatment. This decrease was confirmed in different tumor models and with angiogenesis inhibitors (e.g., RTKIs) other than bevacizumab [73, 79, 80]. In our studies, this decrease was often associated with delayed efflux of chemotherapeutics from tumors [77-79]. The reduced uptake of chemotherapeutics after bevacizumab treatment was corroborated by the reduction of tumor perfusion or vessel permeability, as measured by dynamic contrast enhancement-magnetic resonance imaging (DCE-MRI) [77, 81]. Nevertheless, in all models the combination delayed tumor growth significantly more than single treatment. Thus, one could speculate that angiogenesis inhibitors enhance the efficacy of certain chemotherapeutics by prolonging contact time of drugs with neoplastic cells $[3,79]$. Some studies clearly illustrate the importance of the treatment schedule, showing the temporary time window in which the antiangiogenic agent exerts beneficial effects on drug pharmacokinetics. In fact, drug penetration in tumors was enhanced only when the chemotherapeutic agent was administered within a narrow interval after anti-VEGF therapy (i.e., bevacizumab) [20, 67, 68].

Most of the pharmacokinetic studies in the clinical literature assessed the concentrations of drugs and their metabolites in plasma but not in the tumor. However, the association between the two compartments may not be direct [82]. To our knowledge, only one study in humans describes the effect of antiangiogenic therapy on chemotherapeutic levels in tumors. It was reported that bevacizumab induced rapid, significant reductions in perfusion and $\left[{ }^{11} \mathrm{C}\right]$ docetaxel uptake in NSCLC [83]. This study highlights the importance of drug scheduling and calls for further analysis to optimize combination modalities.

Outcomes differed in relation to the type and molecular weight of the antitumor drug administered after antiangiogenics. Antiangiogenic therapy can improve nanoparticle uptake in a size-dependent manner, with this effect being limited to drugs with a diameter shorter than $10 \mathrm{~nm}$, whereas the tissue penetration of larger molecules (with a diameter longer than $100 \mathrm{~nm}$ ) is prevented [84]. In line with this situation, preclinical studies have shown that the pre-administration of anti-VEGF reduces the intratumoral accumulation of therapeutic antibodies [72-74, 76] and control IgG [76], along with the reductions of tumor blood flow and vessel density.

\section{Effect of anti-VEGF therapy on intratumoral perfusion and drug spatial distribution}

Solid tumors are heterogeneous, not only in terms of cancer cell genotype and phenotype but also in their stromal composition. The tumor microenvironment can physically hinder the penetration of chemotherapy to neoplastic tissue, and inadequate arrival of the effective drug to some cancer cells may cause recurrence or limit the response [85].

An extension of the "normalization" theory supports the idea that hemodynamic changes induced by antiangiogenics lead to more uniform distribution of blood flow and to a reduction of hypoxic/necrotic areas in tumor tissue. This situation would favor more homogeneous intratumoral distribution of anticancer therapies. Our understanding of how antiangiogenic pretreatment affects intratumoral distribution of chemotherapeutic agents is far from complete, since experimental data are scanty. Some imaging techniques have been employed to investigate drug localization in tumor tissue, such as positron emission tomography (PET), single photon emission computed tomography (SPECT), magnetic resonance spectroscopy, autoradiography, fluorescence microscopy, and mass spectrometry imaging (MSI) [82, 86]. In an orthotopic neuroblastoma xenograft model, contrast-enhanced ultrasonography indicated that bevacizumab pretreatment induced more homogeneous contrast enhancement throughout the tumor mass than in controls where enhancement was restricted to the tumor periphery [20]. Accordingly, using longitudinal perfusion computed tomography $(\mathrm{CT})$, sorafenib was shown to favor perfusion in areas that initially showed minimal or no blood flow [87]. A clinical study on hepatocellular carcinoma reported that patients in whom bevacizumab reduced tumor blood flow heterogeneity had a better prognosis [88].

Using histological staining and MSI to visualize paclitaxel localization in tissues, we found that its distribution was inadequate in poorly vascularized areas of tumors, but more homogeneous in the bevacizumabtreated tumors, where there was a reduction of necrotic areas and more functional vascularization [77]. This was observed in different tumor xenografts (ovarian and colon), implanted in different (orthotopic and ectopic) sites, and always associated with not increased paclitaxel concentrations. We had similar results, not only after antiangiogenics but also after chronic pretreatment with low doses of paclitaxel, whose antiangiogenic effect was clearly demonstrated [89], favoring homogeneous intratumoral distribution of a single subsequent high dose of paclitaxel [90]. The improved distribution of paclitaxel in tumor tissue might partly explain the antitumor 


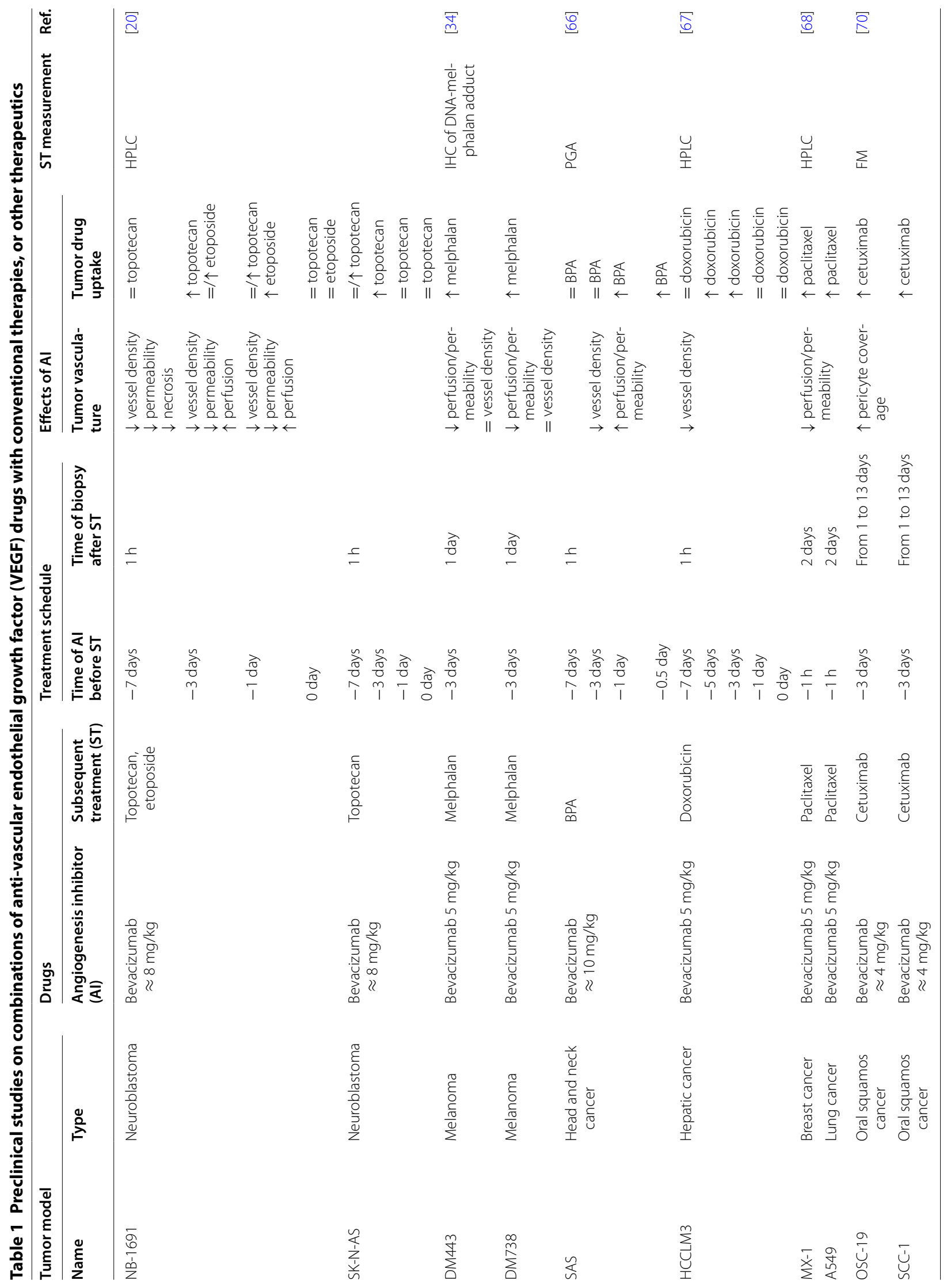




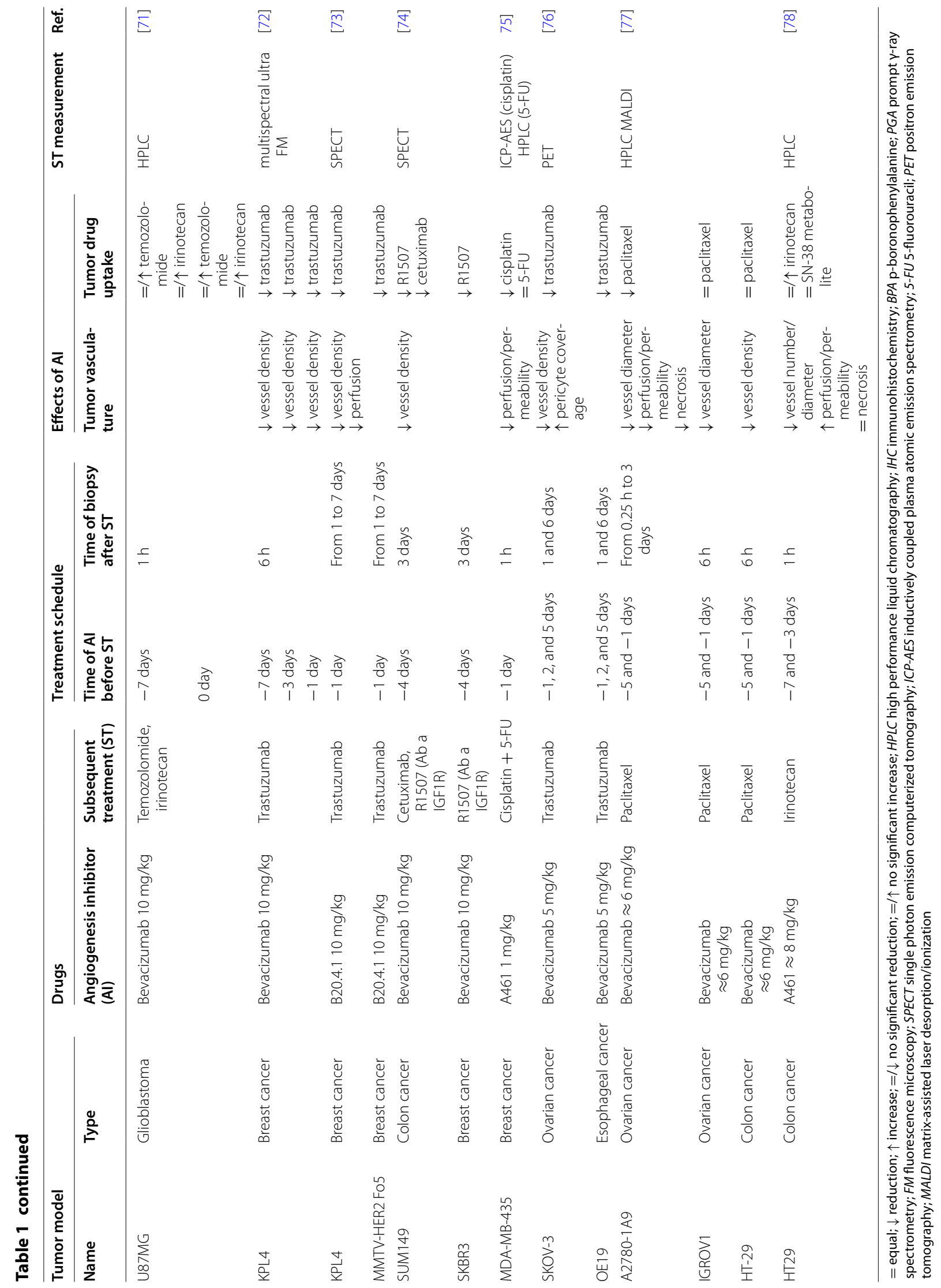


potentiation of the combination with antiangiogenic treatment in solid tumors.

Different results were obtained combining anticancer antibodies with antiangiogenics. A preclinical study using multispectral fluorescence indicated that bevacizumab significantly hampered the penetration of trastuzumab (anti-HER2/neu receptor antibody)-Alexa750 in tumor tissue, despite a more uniform tumor vasculature [72]. The antibody localized solely in the periphery of the bevacizumab-pretreated tumors. Similarly, Pastuskovas et al. [73] showed that anti-VEGF restricted trastuzumab distribution to the tumor margin, consistently with vessel localization. In RIP-Tag2 transgenic mice, the inhibition of VEGF signaling reduced the tumor vascularity. The antibody distribution per surviving tumor vessel was better. Antibodies given after antiangiogenics preferentially accumulate in the sleeves of basement membrane left behind by regressing tumor vessels [91].

\section{Conclusions}

VEGF inhibitors are mainly used in oncology with chemotherapy, but the mechanism by which antiangiogenic agents help chemotherapy is not completely understood. The outcome of using bevacizumab in combination with chemotherapy probably depends on the tumor type and stage and very closely on the dose/schedule of treatment.

It is widely recognized that vessel changes occur after antiangiogenic treatment, but how this can modify vessel patency, TIFP, hypoxia, and ultimately drug uptake and distribution is still not clear. Some preclinical studies reported functional improvement in tumor blood perfusion after angiogenesis inhibitors, with increased tumor exposure to cytotoxic drugs. However, in other studies, tumor vascular patency decreased and hypoxia increased, with impaired cytotoxic drug uptake. The causal relationships between the effect on the microvasculature, the TIFP reduction, and the trans-vascular transport of drugs are still not completely understood.

We have proposed that the greater antitumor activity of paclitaxel after bevacizumab is not necessarily due to high drug concentrations, but to the restoration of a more functional tumor microenvironment that facilitates the distribution of chemotherapy. Whether this holds true for other combination modalities, different angiogenesis inhibitors, and other chemotherapeutics remains to be established. It also needs to be shown whether this paradigm can be translated to patients' tumors under treatment. Monitoring the activity of antiangiogenics is a practical challenge in the clinical setting, where noninvasive imaging procedures need to be improved to monitor the administration and determine the efficacy of antiangiogenesis-based combination regimens in every tumor.
Authors' contributions

IFN and MC drafted the manuscript. FB participated in some of the studies. RG supervised and revised the manuscript. All authors read and approved the final manuscript.

\section{Acknowledgements}

The authors thank J.D. Baggott for editing the manuscript. This study was supported by Grants from the Italian Association for Cancer Research (IG14532 and 12182 to RG) and the Fondazione CARIPLO (No. 2011-0614 to MC). IFN has received a fellowship from the Fondazione Italiana per la Ricerca sul Cancro.

\section{Competing interests}

The authors declare that they have no competing interests.

Received: 12 April 2016 Accepted: 10 May 2016

Published online: 29 June 2016

\section{References}

1. Hanahan D, Weinberg RA. Hallmarks of cancer: the next generation. Cell. 2011;144(5):646-74. doi:10.1016/j.cell.2011.02.013.

2. Heath VL, Bicknell R. Anticancer strategies involving the vasculature. Nat Rev Clin Oncol. 2009;6(7):395-404. doi:10.1038/nrclinonc.2009.52.

3. Cesca M, Bizzaro F, Zucchetti M, Giavazzi R. Tumor delivery of chemotherapy combined with inhibitors of angiogenesis and vascular targeting agents. Front Oncol. 2013;3:259. doi:10.3389/fonc.2013.00259.

4. Ocana A, Amir E, Vera F, Eisenhauer EA, Tannock IF. Addition of bevacizumab to chemotherapy for treatment of solid tumors: similar results but different conclusions. J Clin Oncol. 2011;29(3):254-6. doi:10.1200/ JCO.2010.32.0275.

5. Gaya A, Tse V. A preclinical and clinical review of aflibercept for the management of cancer. Cancer Treat Rev. 2012;38(5):484-93. doi:10.1016/j. ctrv.2011.12.008.

6. Matrana MR, Atkinson B, Jonasch E, Tannir NM. Emerging targeted therapies in metastatic renal cell carcinoma. Curr Clin Pharmacol. 2011;6(3):189-98. doi:10.2174/157488411797189398.

7. Ellis LM, Hicklin DJ. VEGF-targeted therapy: mechanisms of anti-tumour activity. Nat Rev Cancer. 2008;8(8):579-91. doi:10.1038/nrc2403.

8. Giavazzi R, Bani MR, Taraboletti G. Tumor-host interaction in the optimization of paclitaxel-based combination therapies with vascular targeting compounds. Cancer Metastasis Rev. 2007;26(3-4):481-8. doi:10.1007/ s10555-007-9074-y.

9. Heldin $\mathrm{CH}$, Rubin K, Pietras K, Ostman A. High interstitial fluid pressure-an obstacle in cancer therapy. Nat Rev Cancer. 2004;4(10):806-13. doi:10.1038/nrc1456.

10. Carmeliet P, Jain RK. Molecular mechanisms and clinical applications of angiogenesis. Nature. 2011;473(7347):298-307. doi:10.1038/nature10144.

11. Jain RK. Normalizing tumor microenvironment to treat cancer: bench to bedside to biomarkers. J Clin Oncol. 2013;31(17):2205-18. doi:10.1200/ JCO.2012.46.3653.

12. Goel S, Duda DG, Xu L, Munn LL, Boucher Y, Fukumura D, et al. Normalization of the vasculature for treatment of cancer and other diseases. Physiol Rev. 2011;91(3):1071-121. doi:10.1152/physrev.00038.2010.

13. Jayson GC, Hicklin DJ, Ellis LM. Antiangiogenic therapy_evolving view based on clinical trial results. Nat Rev Clin Oncol. 2012;9(5):297-303. doi:10.1038/nrclinonc.2012.8.

14. Batchelor TT, Duda DG, di Tomaso E, Ancukiewicz M, Plotkin SR, Gerstner E, et al. Phase II study of cediranib, an oral pan-vascular endothelial growth factor receptor tyrosine kinase inhibitor, in patients with recurrent glioblastoma. J Clin Oncol. 2010;28(17):2817-23. doi:10.1200/JCO.2009.26.3988.

15. Sorensen AG, Batchelor TT, Zhang WT, Chen PJ, Yeo P, Wang M, et al. A "vascular normalization index" as potential mechanistic biomarker to predict survival after a single dose of cediranib in recurrent glioblastoma patients. Cancer Res. 2009:69(13):5296-300. doi:10.1158/0008-5472.CAN-09-0814.

16. Willett CG, Duda DG, di Tomaso E, Boucher Y, Ancukiewicz M, Sahani DV, et al. Efficacy, safety, and biomarkers of neoadjuvant bevacizumab, radiation therapy, and fluorouracil in rectal cancer: a multidisciplinary phase II study. J Clin Oncol. 2009;27(18):3020-6. doi:10.1200/JCO.2008.21.1771. 
17. Fischer I, Cunliffe CH, Bollo RJ, Raza S, Monoky D, Chiriboga L, et al. High-grade glioma before and after treatment with radiation and Avastin: initial observations. Neuro Oncol. 2008;10(5):700-8. doi:10.1215/15228517-2008-042.

18. Willett CG, Boucher Y, di Tomaso E, Duda DG, Munn LL, Tong RT, et al. Direct evidence that the VEGF-specific antibody bevacizumab has antivascular effects in human rectal cancer. Nat Med. 2004;10(2):145-7. doi:10.1038/nm988.

19. Turetschek K, Preda A, Novikov V, Brasch RC, Weinmann HJ, Wunderbaldinger $\mathrm{P}$, et al. Tumor microvascular changes in antiangiogenic treatment: assessment by magnetic resonance contrast media of different molecular weights. J Magn Reson Imaging. 2004;20(1):138-44. doi:10.1002/jmri.20049.

20. Dickson PV, Hamner JB, Sims TL, Fraga CH, Ng CY, Rajasekeran S, et al. Bevacizumab-induced transient remodeling of the vasculature in neuroblastoma xenografts results in improved delivery and efficacy of systemically administered chemotherapy. Clin Cancer Res. 2007;13(13):3942-50. doi:10.1158/1078-0432.CCR-07-0278.

21. Franco M, Man S, Chen L, Emmenegger U, Shaked Y, Cheung AM, et al. Targeted anti-vascular endothelial growth factor receptor-2 therapy leads to short-term and long-term impairment of vascular function and increase in tumor hypoxia. Cancer Res. 2006;66(7):3639-48. doi:10.1158/0008-5472.CAN-05-3295.

22. von Baumgarten $L$, Brucker D, Tirniceru A, Kienast $Y$, Grau S, Burgold $\mathrm{S}$, et al. Bevacizumab has differential and dose-dependent effects on glioma blood vessels and tumor cells. Clin Cancer Res. 2011;17(19):6192205. doi:10.1158/1078-0432.CCR-10-1868.

23. Rajendran R, Huang W, Tang AM, Liang JM, Choo S, Reese T, et al. Early detection of antiangiogenic treatment responses in a mouse xenograft tumor model using quantitative perfusion MRI. Cancer Med. 2014;3(1):47-60. doi:10.1002/cam4.177.

24. Koukourakis MI, Mavanis I, Kouklakis G, Pitiakoudis M, Minopoulos G, Manolas C, et al. Early antivascular effects of bevacizumab anti-VEGF monoclonal antibody on colorectal carcinomas assessed with functional CT imaging. Am J Clin Oncol. 2007;30(3):315-8. doi:10.1097/01. coc.0000258119.90805.ca.

25. Liu G, Rugo HS, Wilding G, McShane TM, Evelhoch JL, Ng C, et al. Dynamic contrast-enhanced magnetic resonance imaging as a pharmacodynamic measure of response after acute dosing of AG-013736, an oral angiogenesis inhibitor, in patients with advanced solid tumors: results from a phase I study. J Clin Oncol. 2005;23(24):5464-73. doi:10.1200/ JCO.2005.04.143.

26. Yao JC, Phan A, Hoff PM, Chen HX, Charnsangavej C, Yeung SC, et al. Targeting vascular endothelial growth factor in advanced carcinoid tumor: a random assignment phase II study of depot octreotide with bevacizumab and pegylated interferon alpha-2b. J Clin Oncol. 2008;26(8):131623. doi:10.1200/JCO.2007.13.6374.

27. Baar J, Silverman P, Lyons J, Fu P, Abdul-Karim F, Ziats N, et al. A vasculature-targeting regimen of preoperative docetaxel with or without bevacizumab for locally advanced breast cancer: impact on angiogenic biomarkers. Clin Cancer Res. 2009;15(10):3583-90. doi:10.1158/10780432. CCR-08-2917.

28. Wedam SB, Low JA, Yang SX, Chow CK, Choyke P, Danforth D, et al, Antiangiogenic and antitumor effects of bevacizumab in patients with inflammatory and locally advanced breast cancer. J Clin Oncol. 2006;24(5):769-77. doi:10.1200/JCO.2005.03.4645.

29. Guo J, Glass JO, McCarville MB, Shulkin BL, Daryani VM, Stewart CF, et al. Assessing vascular effects of adding bevacizumab to neoadjuvant chemotherapy in osteosarcoma using DCE-MRI. Br J Cancer. 2015;113(9):12828. doi:10.1038/bjc.2015.351.

30. Robinson ES, Khankin EV, Choueiri TK, Dhawan MS, Rogers MJ, Karumanchi SA, et al. Suppression of the nitric oxide pathway in metastatic renal cell carcinoma patients receiving vascular endothelial growth factorsignaling inhibitors. Hypertension. 2010;56(6):1131-6. doi:10.1161/ HYPERTENSIONAHA. 110.160481

31. Azzi S, Hebda JK, Gavard J. Vascular permeability and drug delivery in cancers. Front Oncol. 2013;3:211. doi:10.3389/fonc.2013.00211.

32. Sorensen AG, Emblem KE, Polaskova P, Jennings D, Kim H, Ancukiewicz $\mathrm{M}$, et al. Increased survival of glioblastoma patients who respond to antiangiogenic therapy with elevated blood perfusion. Cancer Res. 2012;72(2):402-7. doi:10.1158/0008-5472.CAN-11-2464.
33. Fadnes HO, Reed RK, Aukland K. Interstitial fluid pressure in rats measured with a modified wick technique. Microvasc Res. 1977;14(1):27-36.

34. Turley RS, Fontanella AN, Padussis JC, Toshimitsu H, Tokuhisa Y, Cho $\mathrm{EH}$, et al. Bevacizumab-induced alterations in vascular permeability and drug delivery: a novel approach to augment regional chemotherapy for in-transit melanoma. Clin Cancer Res. 2012;18(12):3328-39. doi:10.1158/1078-0432.CCR-11-3000.

35. Keunen O, Johansson M, Oudin A, Sanzey M, Rahim SA, Fack F, et al. Anti-VEGF treatment reduces blood supply and increases tumor cell invasion in glioblastoma. Proc Natl Acad Sci USA. 2011;108(9):3749-54. doi:10.1073/pnas.1014480108.

36. Winkler F, Kozin SV, Tong RT, Chae SS, Booth MF, Garkavtsev I, et al. Kinetics of vascular normalization by VEGFR2 blockade governs brain tumor response to radiation: role of oxygenation, angiopoietin-1, and matrix metalloproteinases. Cancer Cell. 2004;6(6):553-63. doi:10.1016/j.ccr.2004.10.011.

37. Jain RK. Antiangiogenesis strategies revisited: from starving tumors to alleviating hypoxia. Cancer Cell. 2014;26(5):605-22. doi:10.1016/j.ccell.2014.10.006.

38. Klement G, Baruchel S, Rak J, Man S, Clark K, Hicklin DJ, et al. Continuous low-dose therapy with vinblastine and VEGF receptor-2 antibody induces sustained tumor regression without overt toxicity. J Clin Invest. 2000;105(8):R15-24. doi:10.1172/JCl8829.

39. Tonra JR, Deevi DS, Corcoran E, Li H, Wang S, Carrick FE, et al. Synergistic antitumor effects of combined epidermal growth factor receptor and vascular endothelial growth factor receptor-2 targeted therapy. Clin Cancer Res. 2006;12(7 Pt 1):2197-207. doi:10.1158/1078-0432.CCR-05-1682.

40. Oliva P, Decio A, Castiglioni V, Bassi A, Pesenti E, Cesca M, et al. Cisplatin plus paclitaxel and maintenance of bevacizumab on tumour progression, dissemination, and survival of ovarian carcinoma xenograft models. Br J Cancer. 2012;107(2):360-9. doi:10.1038/bjc.2012.261.

41. Vredenburgh JJ, Desjardins A, Herndon JE 2nd, Dowell JM, Reardon DA, Quinn $\mathrm{JA}$, et al. Phase II trial of bevacizumab and irinotecan in recurrent malignant glioma. Clin Cancer Res. 2007;13(4):1253-9. doi:10.1158/1078-0432.CCR-06-2309.

42. Giantonio BJ, Catalano PJ, Meropol NJ, O'Dwyer PJ, Mitchell EP, Alberts $S R$, et al. Bevacizumab in combination with oxaliplatin, fluorouracil, and leucovorin (FOLFOX4) for previously treated metastatic colorectal cancer: results from the Eastern Cooperative Oncology Group Study E3200. J Clin Oncol. 2007;25(12):1539-44. doi:10.1200/JCO.2006.09.6305.

43. Saltz LB, Clarke S, Diaz-Rubio E, Scheithauer W, Figer A, Wong R, et al. Bevacizumab in combination with oxaliplatin-based chemotherapy as first-line therapy in metastatic colorectal cancer: a randomized phase III study. J Clin Oncol. 2008;26(12):2013-9. doi:10.1200/JCO.2007.14.9930.

44. Reck M, von Pawel J, Zatloukal P, Ramlau R, Gorbounova V, Hirsh V, et al. Phase III trial of cisplatin plus gemcitabine with either placebo or bevacizumab as first-line therapy for nonsquamous non-small-cell lung cancer: AVAil. J Clin Oncol. 2009;27(8):1227-34. doi:10.1200/JCO.2007.14.5466.

45. Tebbutt NC, Wilson K, Gebski VJ, Cummins MM, Zannino D, van Hazel GA, et al. Capecitabine, bevacizumab, and mitomycin in first-line treatment of metastatic colorectal cancer: results of the Australasian Gastrointestinal Trials Group Randomized Phase III MAX Study. J Clin Oncol. 2010;28(19):3191-8. doi:10.1200/JCO.2009.27.7723.

46. Hurwitz H, Fehrenbacher L, Novotny W, Cartwright T, Hainsworth J, Heim W, et al. Bevacizumab plus irinotecan, fluorouracil, and leucovorin for metastatic colorectal cancer. N Engl J Med. 2004;350(23):2335-42. doi:10.1056/NEJMoa032691

47. Sandler A, Gray R, Perry MC, Brahmer J, Schiller JH, Dowlati A, et al. Paclitaxel-carboplatin alone or with bevacizumab for non-small-cell lung cancer. N Engl J Med. 2006;355(24):2542-50. doi:10.1056/NEJMoa061884.

48. Tewari KS, Sill MW, Long HJ 3rd, Penson RT, Huang H, Ramondetta LM, et al. Improved survival with bevacizumab in advanced cervical cancer. N Engl J Med. 2014;370(8):734-43. doi:10.1056/NEJMoa1309748.

49. Burger RA, Brady MF, Bookman MA, Fleming GF, Monk BJ, Huang H, et al. Incorporation of bevacizumab in the primary treatment of ovarian cancer. N Engl J Med. 2011;365(26):2473-83. doi:10.1056/NEJMoa1 104390.

50. Perren TJ, Swart AM, Pfisterer J, Ledermann JA, Pujade-Lauraine E, Kristensen $\mathrm{G}$, et al. A phase 3 trial of bevacizumab in ovarian cancer. N Engl J Med. 2011;365(26):2484-96. doi:10.1056/NEJMoa1 103799.

51. Stark D, Nankivell M, Pujade-Lauraine E, Kristensen G, Elit L, Stockler M, et al. Standard chemotherapy with or without bevacizumab in advanced ovarian cancer: quality-of-life outcomes from the International Collaboration on Ovarian Neoplasms (ICON7) phase 3 randomised trial. Lancet Oncol. 2013;14(3):236-43. doi:10.1016/S1470-2045(12)70567-3. 
52. Della Pepa C, Tonini G, Pisano C, Di Napoli M, Cecere SC, Tambaro R, et al. Ovarian cancer standard of care: are there real alternatives? Chin J Cancer. 2015;34(1):17-27. doi:10.5732/cjc.014.10274.

53. Hudis CA. Clinical implications of antiangiogenic therapies. Oncology (Williston Park). 2005;19(4 Suppl 3):26-31.

54. Le Serve AW, Hellmann K. Metastases and the normalization of tumour blood vessels by ICRF 159: a new type of drug action. Br Med J. 1972;1(5800):597-601.

55. Jain RK. Normalizing tumor vasculature with anti-angiogenic therapy: a new paradigm for combination therapy. Nat Med. 2001;7(9):987-9. doi:10.1038/nm0901-987.

56. Tredan O, Galmarini CM, Patel K, Tannock IF. Drug resistance and the solid tumor microenvironment. J Natl Cancer Inst. 2007;99(19):1441-54. doi:10.1093/jnci/djm135.

57. Shaked Y, Henke E, Roodhart JM, Mancuso P, Langenberg MH, Colleoni $M$, et al. Rapid chemotherapy-induced acute endothelial progenitor cell mobilization: implications for antiangiogenic drugs as chemosensitizing agents. Cancer Cell. 2008;14(3):263-73. doi:10.1016/j.ccr.2008.08.001.

58. Castelli C, Rivoltini L, Rodolfo M, Tazzari M, Belgiovine C, Allavena P. Modulation of the myeloid compartment of the immune system by angiogenic- and kinase inhibitor-targeted anti-cancer therapies. Cancer Immunol Immunother. 2015;64(1):83-9. doi:10.1007/s00262-014-1576-1.

59. Ebos JM, Lee CR, Cruz-Munoz W, Bjarnason GA, Christensen JG, Kerbel RS. Accelerated metastasis after short-term treatment with a potent inhibitor of tumor angiogenesis. Cancer Cell. 2009;15(3):232-9. doi:10.1016/j. ccr.2009.01.021.

60. Paez-Ribes M, Allen E, Hudock J, Takeda T, Okuyama H, Vinals F, et al. Antiangiogenic therapy elicits malignant progression of tumors to increased local invasion and distant metastasis. Cancer Cell. 2009;15(3):220-31. doi:10.1016/j.ccr.2009.01.027.

61. Qian CN, Tan MH, Yang JP, Cao Y. Revisiting tumor angiogenesis: vessel cooption, vessel remodeling, and cancer cell-derived vasculature formation. Chin J Cancer. 2016;35(1):10. doi:10.1186/s40880-015-0070-2.

62. Rovida A, Castiglioni V, Decio A, Scarlato V, Scanziani E, Giavazzi R, et al. Chemotherapy counteracts metastatic dissemination induced by antiangiogenic treatment in mice. Mol Cancer Ther. 2013;12(10):2237-47. doi:10.1158/1535-7163.MCT-13-0244.

63. Ranieri G, Patruno R, Ruggieri E, Montemurro S, Valerio P, Ribatti D. Vascular endothelial growth factor (VEGF) as a target of bevacizumab in cancer: from the biology to the clinic. Curr Med Chem. 2006;13(16):1845-57.

64. Blagoev KB, Wilkerson J, Stein WD, Motzer RJ, Bates SE, Fojo AT. Sunitinib does not accelerate tumor growth in patients with metastatic renal cell carcinoma. Cell Rep. 2013;3(2):277-81. doi:10.1016/j.celrep.2013.01.015.

65. Ebos JM, Kerbel RS. Antiangiogenic therapy: impact on invasion, disease progression, and metastasis. Nat Rev Clin Oncol. 2011;8(4):210-21. doi:10.1038/nrclinonc.2011.21

66. Kabbinavar F, Hurwitz HI, Fehrenbacher L, Meropol NJ, Novotny WF, Lieberman G, et al. Phase II, randomized trial comparing bevacizumab plus fluorouracil (FU)/leucovorin (LV) with FU/LV alone in patients with metastatic colorectal cancer. J Clin Oncol. 2003;21(1):60-5.

67. Zhou F, Hu J, Shao JH, Zou SB, Shen SL, Luo ZQ. Metronomic chemotherapy in combination with antiangiogenic treatment induces mosaic vascular reduction and tumor growth inhibition in hepatocellular carcinoma xenografts. J Cancer Res Clin Oncol. 2012;138(11):1879-90. doi:10.1007/ s00432-012-1270-7.

68. Liu Y, Suzuki M, Masunaga S, Chen YW, Kashino G, Tanaka H, et al. Effect of bevacizumab treatment on $\mathrm{p}$-boronophenylalanine distribution in murine tumor. J Radiat Res. 2013;54(2):260-7. doi:10.1093/jr//rrs102.

69. Yanagisawa M, Yorozu K, Kurasawa M, Nakano K, Furugaki K, Yamashita Y, et al. Bevacizumab improves the delivery and efficacy of paclitaxel. Anticancer Drugs. 2010;21(7):687-94. doi:10.1097/ CAD.0b013e32833b7598.

70. Chung TK, Warram J, Day KE, Hartman Y, Rosenthal EL. Time-dependent pretreatment with bevacuzimab increases tumor specific uptake of cetuximab in preclinical oral cavity cancer studies. Cancer Biol Ther. 2015;16(5):790-8. doi:10.1080/15384047.2015.1016664.

71. Goldwirt L, Beccaria K, Carpentier A, Idbaih A, Schmitt C, Levasseur C, et al. Preclinical impact of bevacizumab on brain and tumor distribution of irinotecan and temozolomide. J Neurooncol. 2015;122(2):273-81. doi:10.1007/s11060-015-1717-1.
72. Dobosz M, Ntziachristos V, Scheuer W, Strobel S. Multispectral fluorescence ultramicroscopy: three-dimensional visualization and automatic quantification of tumor morphology, drug penetration, and antiangiogenic treatment response. Neoplasia. 2014;16(1):1-13. doi:10.1593/ neo.131848.

73. Pastuskovas CV, Mundo EE, Williams SP, NayakTK, Ho J, Ulufatu S, et al. Effects of anti-VEGF on pharmacokinetics, biodistribution, and tumor penetration of trastuzumab in a preclinical breast cancer model. Mol Cancer Ther. 2012;11(3):752-62. doi:10.1158/1535-7163.MCT-11-0742-T.

74. Heskamp S, Boerman OC, Molkenboer-Kuenen JD, Oyen WJ, van der Graaf WT, van Laarhoven HW. Bevacizumab reduces tumor targeting of antiepidermal growth factor and anti-insulin-like growth factor 1 receptor antibodies. Int J Cancer. 2013;133(2):307-14. doi:10.1002/ijc.28046.

75. Daldrup-Link HE, Okuhata Y, Wolfe A, Srivastav S, Oie S, Ferrara N, et al. Decrease in tumor apparent permeability-surface area product to a MRI macromolecular contrast medium following angiogenesis inhibition with correlations to cytotoxic drug accumulation. Microcirculation. 2004;11(5):387-96. doi:10.1080/10739680490457665.

76. Arjaans M, Oude Munnink TH, Oosting SF, Terwisscha van Scheltinga AG, Gietema JA, Garbacik ET, et al. Bevacizumab-induced normalization of blood vessels in tumors hampers antibody uptake. Cancer Res. 2013;73(11):3347-55. doi:10.1158/0008-5472.CAN-12-3518.

77. Cesca M, Morosi L, Berndt A, Fuso Nerini I, Frapolli R, Richter P, et al. Bevacizumab-induced inhibition of angiogenesis promotes a more homogeneous intratumoral distribution of paclitaxel, improving the antitumor response. Mol Cancer Ther. 2016;15(1):125-35. doi:10.1158/15357163.MCT-15-0063.

78. Wildiers H, Guetens G, De Boeck G, Verbeken E, Landuyt B, Landuyt $W$, et al. Effect of antivascular endothelial growth factor treatment on the intratumoral uptake of CPT-11. Br J Cancer. 2003;88(12):1979-86. doi:10.1038/sj.bjc.6601005.

79. Cesca M, Frapolli R, Berndt A, Scarlato V, Richter P, Kosmehl H, et al. The effects of vandetanib on paclitaxel tumor distribution and antitumor activity in a xenograft model of human ovarian carcinoma. Neoplasia. 2009;11(11):1155-64.

80. Bello E, Taraboletti G, Colella G, Zucchetti M, Forestieri D, Licandro SA, et al. The tyrosine kinase inhibitor E-3810 combined with paclitaxel inhibits the growth of advanced-stage triple-negative breast cancer xenografts. Mol Cancer Ther. 2013;12(2):131-40. doi:10.1158/1535-7163. MCT-12-0275-T.

81. Bello E, Colella G, Scarlato V, Oliva P, Berndt A, Valbusa G, et al. E-3810 is a potent dual inhibitor of VEGFR and FGFR that exerts antitumor activity in multiple preclinical models. Cancer Res. 2011;71(4):1396-405. doi:10.1158/0008-5472.CAN-10-2700.

82. Fuso Nerini I, Morosi L, Zucchetti M, Ballerini A, Giavazzi R, D'Incalci M, et al. Intratumor heterogeneity and its impact on drug distribution and sensitivity. Clin Pharmacol Ther. 2014;96(2):224-38. doi:10.1038/ clpt.2014.105.

83. Van der Veldt AA, Lubberink M, Bahce I, Walraven M, de Boer MP, Greuter $\mathrm{HN}$, et al. Rapid decrease in delivery of chemotherapy to tumors after anti-VEGF therapy: implications for scheduling of anti-angiogenic drugs. Cancer Cell. 2012;21 (1):82-91. doi:10.1016/j.ccr.2011.11.023.

84. Chauhan VP, Stylianopoulos T, Martin JD, Popovic Z, Chen O, Kamoun WS, et al. Normalization of tumour blood vessels improves the delivery of nanomedicines in a size-dependent manner. Nat Nanotechnol. 2012;7(6):383-8. doi:10.1038/nnano.2012.45.

85. Choi IK, Strauss R, Richter M, Yun CO, Lieber A. Strategies to increase drug penetration in solid tumors. Front Oncol. 2013;3:193. doi:10.3389/ fonc. 2013.00193 .

86. Morosi L, Zucchetti M, D'Incalci M, Davoli E. Imaging mass spectrometry: challenges in visualization of drug distribution in solid tumors. Curr Opin Pharmacol. 2013;13(5):807-12. doi:10.1016/j.coph.2013.06.003.

87. Sabir A, Schor-Bardach R, Wilcox CJ, Rahmanuddin S, Atkins MB, Kruskal $J B$, et al. Perfusion MDCT enables early detection of therapeutic response to antiangiogenic therapy. AJR Am J Roentgenol. 2008;191 (1):133-9. doi:10.2214/AJR.07.2848.

88. Hayano K, Lee SH, Yoshida H, Zhu AX, Sahani DV. Fractal analysis of $\mathrm{CT}$ perfusion images for evaluation of antiangiogenic treatment and survival in hepatocellular carcinoma. Acad Radiol. 2014;21(5):654-60. doi:10.1016/j.acra.2014.01.020 
89. Belotti D, Vergani V, Drudis T, Borsotti P, Pitelli MR, Viale G, et al. The microtubule-affecting drug paclitaxel has antiangiogenic activity. Clin Cancer Res. 1996;2(11):1843-9.

90. Morosi L, Spinelli P, Zucchetti M, Pretto F, Carra A, D'Incalci M, et al. Determination of Paclitaxel distribution in solid tumors by nano-particle assisted laser desorption ionization mass spectrometry imaging. PLoS One. 2013;8(8):e72532. doi:10.1371/journal.pone.0072532.
91. Nakahara T, Norberg SM, Shalinsky DR, Hu-Lowe DD, McDonald DM. Effect of inhibition of vascular endothelial growth factor signaling on distribution of extravasated antibodies in tumors. Cancer Res. 2006;66(3):1434-45. doi:10.1158/0008-5472.CAN-05-0923.

\section{Submit your next manuscript to BioMed Central and we will help you at every step:}

- We accept pre-submission inquiries

- Our selector tool helps you to find the most relevant journal

- We provide round the clock customer support

- Convenient online submission

- Thorough peer review

- Inclusion in PubMed and all major indexing services

- Maximum visibility for your research

Submit your manuscript at

www.biomedcentral.com/submit 